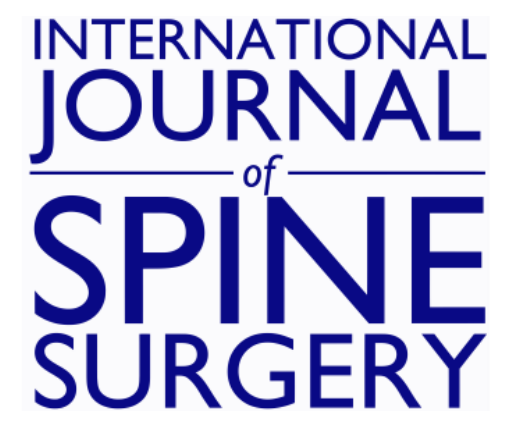

\title{
Intraregional differences of perioperative management strategy for lumbar disc herniation: is the Devil really in the details?
}

Cesare Zoia, Daniele Bongetta, Jacopo C. Poli, Mariarosaria Verlotta, Raffaelino Pugliese and Paolo Gaetani

Int J Spine Surg 2017, 11 (1)

doi: https://doi.org/10.14444/4001

http://ijssurgery.com/content/11/1/1

This information is current as of April 26, 2023.

Email Alerts Receive free email-alerts when new articles cite this article. Sign up at:

http://ijssurgery.com/alerts

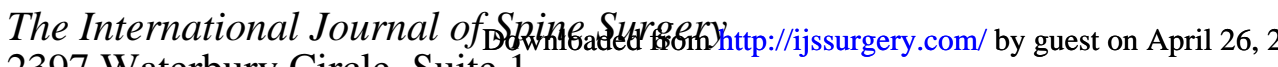
2397 Waterbury Circle, Suite 1,

Aurora, IL 60504, Phone: +1-630-375-1432 


\section{Intraregional differences of perioperative management strategy for lumbar disc herniation: is the Devil really in the details?}

Cesare Zoia MD PhD, 1 Daniele Bongetta MD,1,2 Jacopo C. Poli MD, 3 Mariarosaria Verlotta MD, 2 Raffaelino Pugliese MD, 1 Paolo Gaetani MD 1

${ }_{1}^{1}$ Neurosurgery Unit, Fondazione IRCCS Policlinico S. Matteo, Pavia, Italy, ${ }^{2}$ Neurosurgery, Department of Clinical-Surgical, Diagnostic and Pediatric Sciences, Università degli Studi di Pavia, Pavia, Italy, ${ }^{3}$ Neurosurgery Unit, Ospedale di Circolo e Fondazione Macchi, Varese, Italy

\section{Abstract}

\section{Background}

This study intends to evaluate whether regional common habits or differences in case-volume between surgeons are significative variables in the perioperative management of patients undergoing surgery for lumbar disc herniation.

\section{Methods}

An e-mail survey was sent to all neurosurgeons working in Lombardy, Italy's most populated region. The survey consisted of 17 questions about the perioperative management of lumbar disc herniation.

\section{Results}

Forty-seven percent (47\%) out of 206 Lombard neurosurgeons answered the survey. Although in some respects there is clear evidence in current literature on which is the best practice to adopt for an optimal management strategy, we noticed substantial differences between respondents, not only between hospitals but also between surgeons from the same hospital. Still, no differences were evident in a high vs low case-volume comparison.

\section{Conclusion}

We identified no regional clusterization as for practical principles in the perioperative management of lumbar disc herniation and neither was case-volume a significative variable. Other causes may be relevant in the variability between the perioperative management and the outcomes achieved by different specialists.

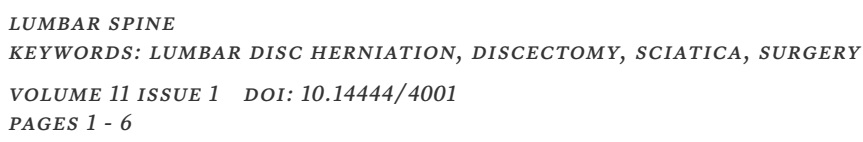

\section{Introduction}

Lumbar disc herniation (LDH) is one of the most common pathologies affecting the adult population. The prevalence of symptomatic LDH is about $2 \%$ : it has been estimated that up to $70 \%$ of male subjects will have symptoms related to this pathology at least once in a lifetime. ${ }^{1}$ The first-line therapy for $\mathrm{LDH}$ is usually conservative, consisting of a combination of rest and/or physical therapy, anti-inflammatory drugs (such as NSAIDs and steroids), muscle relaxants, pain killers and antiepilectic drugs. Surgical therapy is usually indicated when there is a story of low-back pain and/or sciatalgia, associated with positive imaging for $\mathrm{LDH}$ and neurological deficits after a conservative treatment failure. Most of these princiDownloaded from http://ijs ples are accepted by the majority of neurosurgeons, while the perioperative management of this pathology varies considerably. Several features regarding the perioperative management of lumbar disc herniation have been studied in literature with different evidence levels but there is not a practical agreement on many aspects in the global scientific community. Aim of this study is to verify whether there is some agreement, at least at a regional level, and if case-volume is a factor in determining perioperative habits of care. On this purpose we conducted a survey among neurosurgeons operating in Lombardy, Italy's most populated region, with an estimated population of around 10 million people. This choice was made on the assumption that such a survey could represent a regional sample which turns out to be sufficiently 
large and homogenous since all the respondents have the same specialization and practice in the same area.

\section{Materials and Methods}

We located all the fully trained neurological surgeons working in Lombardy in its 22 neurosurgical departments. These last span from relatively small private Hospital settings to large University Hospitals A survey consisting of the following questions was sent to each of them by an e-mail with a link redirecting to a Google Form page which was available on line from September to November 2014:

How many LDH do you operate per year?

Which kind of anesthesia do you use?

Which surgical position do you use?

Do you use a fluoroscope?

Which kind of retractor do you use?

Do you use a microscope or surgical loupes?

Do you inject local anesthetics?

Do you inject glucocorticoids (GCs) periradicularly?

When do you mobilize patients?

In case of unintentional durotomy, do you prolong medical cares?

When do you usually discharge patients?

Do you prescribe a corset during the postoperative period? For how long do you recommend it?

Do you prescribe GCs during the postoperative period?

Do you prescribe opioids and/or NSAIDs during the postoperative period?

Do you prescribe neurotrophic drugs during the postoperative period?
Do you prescribe physiotherapy?

Do you schedule a follow-up visit?

\section{Statistical Methods}

In order to detect any differences between the treatment strategies of high vs low volume surgeon $(>50$ vs $<50$ LDHs operation per year) we performed Chisquare tests, accepting $\mathrm{p}<0.05$ for statistical significance.

\section{Results}

Ninety-seven (47\%) out of the 206 questionnaires were completed by Lombard neurosurgeons. The majority of surgeons operate 20 to $100 \mathrm{LDHs}$ each year: $51.5 \%$ and $28.9 \%$ of surgeons perform 20 to 50 and 50 to 100 operations each year respectively; $18.6 \%$ of surgeons make less than 20 operations each year, 1 surgeon reported more than 100 LDHs in a year. The most relevant variables considered are presented in Table 1.

The vast majority of surgeons $(90.7 \%)$ operate with general anesthesia. Roughly half of the responders (56.7\%) use a surgical positioning frame to enhance lumbar kyphosis (e.g. Wilson frame); $35.1 \%$ and 8.2\% of surgeons prefer a Knee-Chest position or a simple prone position with pillows, respectively. Caspar, Taylor and Williams retractor systems are used as for frequency of employment $(68.0 \%, 20.6 \%, 11.4 \%)$. The vast majority of the surgeons (82.5\%) use a microscope or surgical loupes during the operations. $90.7 \%$ of surgeons use the fluoroscope. $68 \%$ of surgeons use local anesthetics: $66.7 \%$ pre-operatively only, $27.3 \%$ at the end of intervention and $6 \%$ both pre-operatively and at the end of intervention. 23.7\% inject periradicular GCs. Considering the post-operative period, only $23.7 \%$ of surgeons start mobilizing patients on the same day of the operation, whereas others prefer to wait for the following day. $24.7 \%$ of surgeons recommend the use of an orthopedic corset: among them $75 \%$ prefer a lumbar elastic band whereas a $25 \%$ prefer a rigid corset. Corsets are prescribed for 15 days by $48.4 \%$ of surgeons, 1 month by $29 \%$, over 1 month by $22.6 \%$. The patient is usually discharged during the $1^{\text {st }}, 2^{\text {nd }}$ or $3^{\text {rd }}$ (or more) day after the operation by $25.8 \%, 66.0 \%$ and $8.2 \%$ surgeons respectively. When 
an unintended durotomy occurs, $59.8 \%$ of surgeons prolong hospitalization for 1 day, $14.4 \%$ for 2 days or more, and $25.8 \%$ do not prolong patient hospitalization. GCs, opioids and/or NSAIDs and neurotrophic medications are routinely prescribed by $46.4 \%, 7.2 \%$ and $11.3 \%$ of surgeons respectively. Physiotherapy is prescribed only by roughly half of the surgeons: $12.2 \%$ recommend its beginning 15 days post surgery, 87.8\% after 1 month. Patients are routinely seen in outpatient clinics for the follow-up: 65.0\% 1 month after the operation; $10.3 \%$ after 3 months, $24.7 \%$ only at patients's request. From a comparison between the results yielded by high case-volume surgeons (i.e $\geq 50$ $\mathrm{LDH}$ intervention per year) and those with a low-

\begin{tabular}{|c|c|c|}
\hline \multicolumn{2}{|l|}{ Perioperative variables } & $\%$ \\
\hline \multirow{2}{*}{ Anesthesia } & General & 90.7 \\
\hline & Spinal & 9.3 \\
\hline \multirow{3}{*}{ Surgical positioning } & Flexed & 56.7 \\
\hline & Knee-Chest & 35.1 \\
\hline & Simple prone & 8.2 \\
\hline \multirow{2}{*}{ Fluoroscope use } & Yes & 90.7 \\
\hline & No & 9.3 \\
\hline \multirow{3}{*}{ Retractor use } & Caspar & 68 \\
\hline & Taylor & 20.6 \\
\hline & Williams & 11.4 \\
\hline \multirow{2}{*}{ Microscope or loupes } & Yes & 82.5 \\
\hline & No & 17.5 \\
\hline \multirow{4}{*}{ Local anesthetics } & No & 32 \\
\hline & Pre-op & 45.3 \\
\hline & Post-op & 18.6 \\
\hline & Pre + Post & 4.1 \\
\hline \multirow{2}{*}{ Periradicular Gcs } & Yes & 23.7 \\
\hline & No & 76.3 \\
\hline \multirow{2}{*}{ Day of mobilization } & 0 & 23.7 \\
\hline & $>0$ & 76.3 \\
\hline \multirow{3}{*}{ Prolonged hospitalization days after durotomy } & 0 & 25.8 \\
\hline & 1 & 59.8 \\
\hline & $>1$ & 14.4 \\
\hline \multirow{3}{*}{ Day of discharge } & 1 & 25.8 \\
\hline & 2 & 66 \\
\hline & $>2$ & 8.2 \\
\hline \multirow{4}{*}{ Days of corset prescription } & 0 & 75.3 \\
\hline & 15 & 11.9 \\
\hline & 30 & 7.2 \\
\hline & $>30$ & 5,6 \\
\hline \multirow{2}{*}{ GCs prescription } & Yes & 46.4 \\
\hline & No & 53.6 \\
\hline \multirow{2}{*}{ Opioids and/or NSAIDs prescription } & Yes & 7.2 \\
\hline & No & 92.8 \\
\hline \multirow{2}{*}{ Neurotrophic drugs prescription } & Yes & 11.3 \\
\hline & No & 88.7 \\
\hline \multirow{3}{*}{ Physiotherapy beginning day } & Never & 50 \\
\hline & 15 & 6.1 \\
\hline & 30 & 43.9 \\
\hline \multirow{3}{*}{ Follow-up visit } & $1 \mathrm{mo}$ & 65 \\
\hline & $3 \mathrm{mo}$ & 10.3 \\
\hline & on request & 24.7 \\
\hline
\end{tabular}

case volume, we gathered that there were no statistically significative differences for any of the items of the questionnaire.

\section{Discussion}

A review of literature was performed searching the reported guidelines on management of low back pain and sciatica for perioperative management reccomendations. ${ }^{2-5}$ Little to no information is available on this particular topic. In particular a general lack of an evidence-based approach is noticeable. Also in the largest international case series, when reported, the subtle nuances of perioperative management seems to be determined by surgeons' comfort and common habit.Indeed, although LDH is one of the most common pathologies in the neurosurgical practice, there are still many non-common routines among neurosurgeons: surprisingly, in accordance to the global literature, also the results of our regional survey showed that there is not a standard perioperative treatment routine. In particular, we did retrieve different answers from practitioners of the same hospital and we could not detect any specific trend related to the personal, yearly case-volume. Even when there is a clear evidence or, at least, an indication in literature on the best treatment strategy, there wasn't always a common practice by the majority of surgeons. Specifically, as early as the first clinical question, even though a recent review ${ }^{6}$ showed the benefits of loco-regional anesthesia compared to general anesthesia, only $10 \%$ of neurosurgeons use this option. As for the positioning issues there is instead conflicting data in literature: Rigamonti et al. ${ }^{7}$ report that the prone and knee chest positions are equivalent, whereas Akinci et al. ${ }^{8}$ showed more benefits with a jack-knife position. This uncertainty is reflected on the answers reported. Even in the case where there is a precise medico-legal indication, as for the use of a fluoroscope for the confirmation of the lumbar level to be operated, almost 9\% of the surgeons did not report this practice. Moreover, the majority of neurosurgeons use the microscope or surgical loupes but as much as $17,5 \%$ don't use any magnifying device even though microdiscectomy showed its advantages as early as 1977 when was popularized by Yasargil and Caspar. ${ }^{9,10}$ Although it can be inferred that the preference in use of a particular retractor over anoth- 
er is simply a matter of personal or institutional habits, we believe that at least a choice of a magnification method must be made, since modern neurosurgical practices should always imply an adequate visual aid. The effectiveness of both topic GCs and local anesthetics has been well documented in literature, ${ }^{11-14}$ nevertheless they are used only by $23 \%$ and $68 \%$ of surgeons, respectively. As for the mobilization issues, although there is no clear indication in literature, we noticed a clear tendency to mobilize the patients on the day after the operation and discharge them on the $1^{\text {st }}$ or $2^{\text {nd }}$ post-op day; moreover, orthopedic corsets are prescribed by up to $25 \%$ of surgeons. In accordance with literature, most surgeons do not excessively prolong the hospitalization in case of unintended durotomy. ${ }^{15,16}$ Post-operative medical therapy is another controversial aspect: GCs are prescribed by $45 \%$, whereas opioids and neurotrophic drugs are given by only $7 \%$ and $11 \%$, respectively. These trends are in conflict with the most recent literature evidence..$^{17-19}$ Lastly, physiotherapy is routinely prescribed by almost $50 \%$ of surgeons and only $65 \%$ schedule a post-op follow-up at the time of discharge. Since this analysis has not revealed a substantial regional common practice in the perioperative management of $\mathrm{LDH}$, we reckon that other factors may be implied in the differences of attitude between surgeons. The 22 departments of Neurosurgery have different case-loads and, more specifically, different surgeons perform LDH operations with variable frequencies. In this regard it must be said that most of our respondents operate less than 1 $\mathrm{LDH}$ per week (only $29 \%$ operate more than $50 \mathrm{LDH}$ per year) and yet, in a similar study, ${ }^{20}$ almost $70 \%$ of surgeons are said to operate more than $50 \mathrm{LDHs}$ per year. Literature data has demonstrated that even for spinal surgery, the frequency of performing a given procedure is directly related to an increase in good results, in terms of satisfactory outcome and low complication rates. ${ }^{21}$ On these premises we performed a comparison between the perioperative strategies adopted by high-volume surgeons (i.e. $\geq 50$ cases per year) and those by low-volume ones. Surprisingly, no statistically significant differences were evident in any of the investigated items between the two groups. The fact that no specific trend was evident comparing the two groups may infer that even theoretically more expert surgeons share no relevant routine to optimize peri-operative cares. In particular, apart from some basic recommendations (e.g., fluoroscopic checks, magnification), all of the other perioperative issues may not be as relevant as a good, state-of-the-art, central surgical time. We look forward to the results of a still ongoing, European Survey proposed via EANS by Dutch Authors wellrenowned on this topic, ${ }^{22}$ in order to compare our results on a bigger scale. New studies are, in fact, needed to evaluate the relevance of the numerous variables to account in the management of such a frequent disease. Paraphrasing a common proverb: the Devil may not be in the details but in adequate surgical skills.

\section{Conclusions}

We retrieved significative differences in almost every aspect of the perioperative management of $\mathrm{LDH}$ in the neurosurgical community of a single, highlypopulated region of Italy. Analyzing the data we have reported no evident regional habit nor could we assess that the case-volume by a single surgeon is a decisive variable for a defined treatment strategy. Further studies are needed to better understand the adequate perioperative management and its relevance in terms of outcome for the patients.

\section{Acknowledgements}

The Authors would like to thank Davide Bongetta for his linguistic assistance.

\section{References}

1. Saunders WB: Surgical indications and tecniques, in Hanley E (2nd ed.) : The lumbar spine. Philadelphia, 1996, pp. 492-524

2. Kreine DS, Hwang SW, Easa JE, Resnick DK, Baisden JL, Bess S, et Al. North American Spine Society. An evidence-based clinical guideline for the diagnosis and treatment of lumbar disc herniation with radiculopathy. Spine J. 2014 Jan;14(1):180-91. doi: 10.1016/j.spinee.2013.08.003. Epub 2013 Nov 14. Review

3. van Tulder M, Becker A, Bekkering T, Breen A, del Real MT, Hutchinson A, et al. European guide-

Downloaded from http://ijssurgery.com/ by guest on April 26, 2023 
lines for the management of acute nonspecific low back pain in primary care. Eur Spine J. 2006;15:S169-191. doi: 10.1007/s00586-006-1071-2 4. Airaksinen O, Brox JI, Cedraschi C, Hildebrandt J, Klaber-Moffett J, Kovacs F, et al. European guidelines for the management of chronic nonspecific low back pain. Eur Spine J. 2006;15:S192-300. doi: 10.1007/s00586-006-1072-1

5. Koes BW, van Tulder MW, Peul WC. Diagnosis and treatment of sciatica. BMJ. 2007;334:1313-1317. doi: 10.1136/bmj.39223.428495.BE

6. De Rojas JO, Syre P, Welch WC: Regional anesthesia versus general anesthesia for surgery on the lumbar spine: a review of the modern literature. Clin Neurol Neurosurg, 2014 119:39-43. doi: 10.1016/ j.clineuro.2014.01.0167

7. Rigamonti A, Gemma M, Rocca A, Messina M, Bignami E, Beretta L: Prone versus knee-chest position for microdiscectomy: a prospective randomized study of intra-abdominal pressure and intraoperative bleeding. Spine (Phila Pa 1976), 2005 30(17):1918-23 8. Akinci IO, Tunali U, Kyzy AA, Guresti E, Sencer A, Karasu A, et al.: Effects of prone and jackknife positioning on lumbar disc herniation surgery. J Neurosurg Anesthesiol, 2011 23(4):318-22. doi: 10.1097/ ANA.0b013e31822b4f17

9. Caspar W: A new surgical procedure for lumbar disc herniation causing less tissue damage through a microsurgical approach. Adv Neurosurg, 1977 4:74-80

10. Yasargil MG: Microsurgical operations for herniated lumbar disc. Adv Neurosurg, 1977 4:81-82 11. Aljabi Y, El-Shawarby A, Cawley DT, Aherne T: Effect of epidural methylprednisolone on postoperative pain and length of hospital stay in patients undergoing lumbar microdiscectomy. Surgeon, 2015 13(5):245-9. doi: 10.1016/j.surge.2014.03.012 12. Jamjoom BA, Jamjoom AB: Efficacy of intraoperative epidural steroids in lumbar discectomy: a systematic review. BMC Musculoskelet Disord, 2014 15:146. doi: 10.1186/1471-2474-15-146 13. Jirarattanaphochai $K$, Jung $S$, Thienthong $S$, Krisanaprakornkit W, Sumananont C: Peridural methylprednisolone and wound infiltration with bupivacaine for postoperative pain control after posterior lumbar spine surgery: a randomized doubleblinded placebo-controlled trial. Spine (Phila $\mathrm{Pa}$
1976), 2007 32(6):609-16

14. Rasmussen S, Krum-Møller DS, Lauridsen LR, Jensen SE, Mandøe H, Gerlif C, et al.: Epidural steroid following discectomy for herniated lumbar disc reduces neurological impairment and enhances recovery: a randomized study with two-year followup. Spine (Phila Pa 1976), 2008 33(19):2028-33. doi: 10.1097/BRS.0b013e3181833903

15. Khan MH, Rihn J, Steele G, Davis R, Donaldson WF 3rd, Kang JD, et al.: Postoperative management protocol for incidental dural tears during degenerative lumbar spine surgery: a review of 3,183 consecutive degenerative lumbar cases. Spine (Phila Pa 1976), 2006 31(22):2609-13

16. Than KD, Wang AC, Etame AB, La Marca F, Park P: Postoperative management of incidental durotomy in minimally invasive lumbar spinal surgery. Minim Invasive Neurosurg, 2008 51(5):263-6. doi: 10.1055/s-0028-1082313

17. Jirarattanaphochai K, Jung S: Nonsteroidal antiinflammatory drugs for postoperative pain management after lumbar spine surgery: a meta-analysis of randomized controlled trials. J Neurosurg Spine, 2008 9(1):22-31. doi: 10.3171/SPI/2008/9/7/022.

18. Manniche C, Lauritsen B, Vinterberg H: Peroperative prednisolone fails to improve the clinical outcome following surgery for prolapsed lumbar intervertebral disc. A randomized controlled trial. Scand J Rheumatol, 1994 23(1):30-5

19. Ozgencil E, Yalcin S, Tuna H, Yorukoglu D, Kecik Y: Perioperative administration of gabapentin $1,200 \mathrm{mg}$ day- 1 and pregabalin $300 \mathrm{mg}$ day- 1 for pain following lumbar laminectomy and discectomy: a randomised, double-blinded, placebo-controlled study. Singapore Med J, 2011 52(12):883-9

20. Arts MP, Peul WC, Koes BW, Thomeer RT: Leiden-The Hague Spine Intervention Prognostic Study (SIPS) Group. Management of sciatica due to lumbar disc herniation in the Netherlands: a survey among spine surgeons. J Neurosurg Spine, 2008 9(1):32-9. doi: 10.3171/SPI/2008/9/7/032 21. Dasenbrock HH, Clarke MJ, Witham TF, Sciubba DM, Gokaslan ZL, Bydon A: The impact of provider volume on the outcomes after surgery for lumbar spinal stenosis. Neurosurgery, 2012 70(6):1346-53. doi: 10.1227/NEU.0b013e318251791a 22. Peul W, van Tulder M, Harhangi S, Arts M: 
Survey on the treatment of lumbar disk herniation. An international view.

(https://nl.surveymonkey.com/r/729K6X9) [Accessed 7 December 2015]

\section{Disclosures \& COI}

The Authors report no conflicts of interest.

\section{Corresponding Author}

Cesare Zoia, Neurosurgery Unit, Fondazione IRCCS
Policlinico S. Matteo, Viale Golgi 19, 27100 Pavia, Italy. gioiaoffice@gmail.com.

Published 9 January 2017.

This manuscript is generously published free of charge by ISASS, the International Society for the Advancement of Spine Surgery. Copyright @ 2017 ISASS. To see more or order reprints or permissions, see http://ijssurgery.com. 